\title{
Positive Consequences: The Impact of an Undergraduate Course on Positive Psychology
}

\author{
Kimberly E. Kleinman' ${ }^{1}$ Craig Asselin², Gregg Henriques ${ }^{3}$ \\ ${ }^{1}$ Department of Pediatric Psychiatry, New York-Presbyterian Hospital, Columbia University Medical Center, \\ New York, USA \\ ${ }^{2}$ University Counseling Center, Florida State University, Tallahassee, USA \\ ${ }^{3}$ Department of Graduate Psychology, James Madison University, Harrisonburg, USA \\ Email: kkleinm@nyspi.columbia.edu, casselin@fsu.edu, henriggx@jmu.edu
}

Received 25 September 2014; revised 21 October 2014; accepted 14 November 2014

Copyright (C) 2014 by authors and Scientific Research Publishing Inc.

This work is licensed under the Creative Commons Attribution International License (CC BY).

http://creativecommons.org/licenses/by/4.0/

(c) (i) Open Access

\begin{abstract}
With the rise of positive psychology and burgeoning evidence base, graduate and undergraduate institutions are now teaching positive psychology as an academic course. Little is known however about its effects. Therefore, the current study sought to develop a positive psychology course conceptually grounded in theory, while also exploring the extent to which the course impacted student well-being. The 25 students enrolled in the class, and a second group of 26 students who were enrolled in alternative psychology course elective (controls), completed a battery of wellbeing measures prior to taking the course, upon completion of the course and at a four-month follow-up. Responses were compared both between- and within-groups and results were promising as significant improvements on a number of measures were found for the intervention group but not for the control group. The implications and limitations of the current research are discussed.
\end{abstract}

\section{Keywords}

Well-Being, Positive Psychology, Undergraduate, Education, Intervention, Group Psychotherapy

\section{Introduction}

With the burgeoning research on positive psychology and well-being, the teaching and the implementation of positive psychology interventions in classrooms has been widely advocated (e.g., Pawelski, 2003). In addition to pedagogical reasons, the idea of teaching positive psychology has been suggested to potentially foster increased 
life satisfaction and purpose, to function as an antidote to depression, and/or improve resilient coping (Seligman, Ernst, Gillham, Reivich, \& Linkins, 2009). Furthermore, consistent with the broaden-and-build theory of positive emotions (Fredrickson \& Branigan, 2005) and the evidence that happiness leads to better learning and academic success (Seligman et al., 2009; Ryan \& Deci, 2001; Lyubomirsky, King, \& Diener, 2005; Quinn \& Duckworth, 2007), it is also a possibility that the teaching of positive psychology interventions would improve the capacity for, or quality of learning.

The relationship between well-being and successful functioning in a wide variety of domains has been welldocumented (Sin \& Lyubomirsky, 2009; Lyubomirsky et al., 2005). This finding, along with the inherent goal of colleges and universities to prepare students for future success, has led researchers such as Oades, Robinson, Green, \& Spence (2011) to suggest institutions of higher education to be a uniquely suited environment for enhancing well-being. If implemented, not only may this result in a strengthened understanding of the scientific principles of well-being across universities, but also, it may better assist students in reaching their potential (Oades et al., 2011). This claim is further supported by Seligman et al. (2009) who recognize that teaching well-being in secondary schools may help to combat depression, increase one's level of life satisfaction, and facilitate learning and creative thinking. Despite this potentially ideal environment for the fostering of well-being, colleges and universities are often structured in a way that is high-striving and competitive, and curricular attention is placed on traditional academics, with few, if any, lessons aimed at improving well-being.

While traditionally, this may have sufficed, several epidemiological studies have noted a recent increase in the incidence and severity of student mental health problems across colleges and universities (Gallagher, 2003; American College Health Association, 2013). Specifically, in 2013 the American College Health Association (ACHA) surveyed over 150 institutions and over ninety-five thousand students. In terms of symptoms of depression and anxiety, the survey found that in the past year, $57 \%$ of women and $40 \%$ of men reported experiencing episodes of "overwhelming anxiety." Thirty four percent of women and $27 \%$ of men reported a period in the last year of feeling "so depressed that it was difficult to function" and 39\% of men and $50 \%$ of women reported feeling hopeless. When asked if suicide had been seriously considered in the past year, $7.4 \%$ of men and $8.1 \%$ of women responded affirmatively with reported suicide attempts around $1.6 \%$ across genders. These alarming percentages represent significant increases from previous decades (American College Health Association, 2013). Although there are possible methodological limitations with cross-generational comparisons and self-report measures, this brief review demonstrates trends of declining mental health amongst college students.

This increase in prevalence of mental health needs, along with the traditional culture of academic demands, further suggests a movement toward "positive education" on college campuses. Positive education has been defined by Seligman et al. (2009) as, "education for both traditional skills and happiness" (p. 293) and by Oades et al. (2011) as, "the development of educational environments that enable the learner to engage in established curricula in addition to knowledge and skills to develop their own and others' well-being” (p. 432). Gallagher (2003) also recognizes this demand and calls for evidence-based and cost-effective mental health services on college campuses. Following this lead, the teaching of positive psychology is becoming more commonly taught at the undergraduate and graduate level. So much so that positive psychology as a college course has received enough attention to warrant its own special edition journal (The Journal of Positive Psychology Special Issue: Positive Psychology in Higher Education).

Now that positive psychology is becoming a standard part of the curriculum, the next step is to evaluate the impact that such courses are having on students and to see if enrollment in a positive psychology course effectively differs from enrollment in a calculus course or a psychopathology course in terms of well-being. We were able to locate literature describing two studies that explored the effectiveness of positive psychology interventions at the undergraduate level and both were identified as initial studies that suggested future research directions.

In 2002 Vanderbilt University created an initiative to support character development in a strategic plan that called for a "new curriculum in moral reasoning, ethical values, and the role of the individual in a democracy... [that urges] consideration of a distinctive and challenging curriculum in moral reasoning, ethics, and character development" (Pawelski, 2003: p. 10). The plan was cross disciplinary and targeted various schools within Vanderbilt's campus. As part of the plan, James Pawelski was hired and he created a course-The Foundations of Character Development.

Pawelski's course drew upon philosophy, psychology and applied human development with the aim of providing students a better understanding and cultivation of character. William James' views on habit formation were used as a building block of the course as students were helped to become aware of their habits and were 
encouraged to reinforce positive habits while breaking negative ones. Specifically, through readings, discussions and experiential learning, somatic habits, linguistic habits, habits of focus, and habits of belief were examined [see Pawelski (2003) for a more detailed review of his course]. Initial analysis of the course revealed significant $(p<.01)$ pre/post changes on the Life Orientation Test, the Beck Hopelessness Scale, the Hope Scale, and on composite scores of the Attributional Style Questionnaire. Additionally, students rated the course highly favorable by providing a course rating of 4.78 out of 5.0 on a measure of social validity. In sum, preliminary findings suggested that the class aimed at improving character development had positive effects on students. Pawelski points out that these are preliminary findings and additional analyses and future repetitions are needed; no additional studies were available at the time of this review.

In a second study, Arkoff, Meredith, Bailey, Cheang, Dubanoski, Griffin and Niyekawa (2006) tested the effectiveness of a life-review group as a means to increase well-being in post-secondary students. Participants were college freshmen enrolled in an introductory psychology course and were assigned either to the experimental life-review group or a control group. The life-review group was a 14-week group that met for 50 minutes each week and used The Illuminated Life: Your Lifebook (Arkoff, 1999) as the curriculum. Different from traditional positive psychology interventions, this curriculum led students through 14 "life questions" and subsequent exercises. Pre- and post-group analyses revealed significant increases for the life-review group on two of the six Ryff scales of psychological well-being [i.e., self-acceptance scale $(p<.01)$ and environmental mastery $(p<.001)]$ but non-significant changes in the comparison group, suggesting that participants in the life-review group had enhanced views of themselves and their ability to effectively manage their environments, but lacked other overall markers of well-being.

With these studies as initial explorations into the effects of teaching a positive psychology course, the current study was created and the following hypotheses were generated. First, the course will have a minimal, but positive, impact on measures of well-being. This will be assessed by comparing the experimental and control conditions in terms of qualitative data, standardized self-report measures of well-being, and a standardized structured interview of well-being. Data will be obtained prior to intervention (T1), after the intervention (T2) and at follow-up (T3). Second, that data collected at T3 will not statistically differ from data collected at T2 suggesting that any changes observed from T1 to T2 will remain. Overall, the current study sought to further explore whether the well-being of undergraduate students could be improved within the context of a course designed to foster awareness of, and improvements in, areas covered by positive psychology. As such, a course was created aimed at not only teaching the concepts of positive psychology, but also assessing and improving the well-being of students within the context of the course.

\section{Method}

The current study sought to determine whether an undergraduate Positive Psychology course could impact self-reported and clinician-rated well-being for enrolled students. In terms of research design, we utilized both a within-and between-groups design. We analyzed the changes students experienced within the course over time and we compared students who took the experimental course with individuals who were in an elective psychology course.

Students in both courses completed a battery of measures at course entry (pre-test) and course completion (post-test) and then a follow-up assessment was conducted approximately four months later to determine whether effects were maintained. A schematic representation of the assessment points that enabled our research design is presented in Table 1. Data were analyzed using two-way repeated-measures ANOVAs and paired samples t-tests.

Table 1. Schematic representation of the research design.

\begin{tabular}{cccc}
\hline & Time 1 & Time 2 & Follow up \\
\hline Satisfaction with life scale & XC & XC & XC \\
PANAS & XC & XC & XC \\
Rosenberg self esteem scale & XC & XC & XC \\
Oxford happiness questionnaire & XC & XC & XC \\
The well-being interview & XC & XC & \\
Supplemental coping questions & XC & XC & \\
\hline
\end{tabular}

Note: $\mathrm{X}=$ completed by the experimental condition; $\mathrm{C}$ = completed by the control condition. 


\subsection{Procedure: The Positive Psychology Course}

A positive psychology course was developed that consisted of four main components: 1) course lectures; 2) small group discussions; 3) the personal project; and, 4) traditional course assignments.

The fourteen-week course met once weekly for two and a half hours. The course included eleven weeks of content classes, one class where students completed a midterm, one intake/orientation class, and one exit/ debriefing class. Class time was divided into two components. The first component, lasting 90 minutes, was didactic and that of a typical discussion-based lecture devoted to a pedagogical review of the intellectual content. In this component, current research on positive psychology and well-being was covered, with particular focus on the practical application of psychological theories and behavior change techniques to enhance personal awareness and self-development.

During the second component, students were then randomly arranged into four small groups of six students. Students remained in the same group, which lasted in duration for one hour and was facilitated by one of four doctoral-level clinicians. The purpose of the small groups was to allow students the opportunity to engage in the course material in a more hands-on, personally relevant way, and to have the opportunity to discuss the extent to which they felt the information might apply to them personally. Based on the weekly topic, and with the support the group leader, students were asked to reflect on personal experiences, as they were comfortable.

The personal project, which comprised $25 \%$ of the student's overall grade, was a project that focused on self-reflective examination of each student's well-being. It consisted of a baseline self-assessment of well-being, weekly homework and journaling and follow-up self-assessment, which were then put together with an overall reflection. Upon completion of the follow-up assessment students were provided a summary of their scores to be used as personal data for their project. The personal project also required successful completion of weekly homework and journals. The homework assignments were not academic in nature, but consisted of empirically supported self-interventions designed to improve a particular domain of well-being and adjustment. In addition to completing the self-intervention, students were asked to document and reflect (journal) on the task and prompts were provided related to the weekly topic and/or homework assignment. To more clearly explicate the structure of the course, a description of the components from week two is provided as a sample in the Appendix (Table A1). Additionally, readers can contact writers for a more detailed description of course content.

\subsection{Participants}

Study participants were initially comprised of 57 undergraduate students enrolled at a large southeastern university. A convenience sampling technique was utilized to form the experimental and control groups. Both courses were offered by the undergraduate psychology department and were credited as an elective towards the undergraduate major in psychology.

\subsubsection{Experimental Group}

The experimental group participants were recruited from students enrolled in a fall 2011 positive psychology course. The dual functionality of course requirements (i.e., typical course assignments and request for research participation) was communicated to students prior to their enrolling in the course and again discussed during the first class. Students enrolled in the course transitioned to research participants only if they understood and agreed to the conditions; all students enrolled in the course consented to participate in the current research project. As such, 25 participants were included in the experimental group (19 females, 6 males; $M_{\text {age }}=20.32$ years, $S D=4.55$, range: 18 - 42 years). Twenty-four of the 25 participants were between the ages of 18 and 20 . Sixteen students were enrolled as sophomores and nine students were enrolled as juniors. Twenty-three students identified their ethnicity as White, one as Asian American, and one as "other", specifying "mixed/multicultural".

\subsubsection{Control Group}

Convenience sampling was used to recruit for the control group as professors of psychology elective courses agreed to offer their students extra credit in exchange for participation in the study. During the intake assessment, thirty-two participants were included in the control group (26 females, 6 males, $M_{\text {age }}=20.63$ years, $S D=1.48$, age range: 18 - 26 years). Two students were enrolled as sophomores, 17 students were enrolled as juniors, 12 students were enrolled as seniors and one student declared being a "fifth year" senior. Twenty-eight students 
identified their ethnicity as White, two as Black, and two as Asian American. Twenty-six of the original 32 participants (21 females, 5 males) completed the exit interview, representing a $79 \%$ retention rate. The 26 students ranged in age from 18 to $23(M=20.46, S D=1.14)$. There was one sophomore, 15 juniors, nine seniors and one "fifth year" senior.

\subsubsection{Follow-Up}

In the experimental condition, 17 of the original 25 participants (14 females, 3 males) completed the follow-up questionnaire, representing a $68 \%$ retention rate. The students ranged in age from 18 to $42(M=20.7, S D=5.5)$. Similarly 14 of the 26 participants (14 females, 0 males) in the control condition completed the follow-up questionnaire, representing a 54\% retention rate. The students ranged in age from 18 to $22(M=20.1, S D=.997)$.

\subsection{Measures}

Participants in both conditions were administrated the battery of measures twice (time one, time two) and then a shortened version was administered at follow-up (time three). The battery consisted of five measures, including five self-report measures and a structured interview. The follow-up battery consisted of the five self-report measures. The Scales of Psychological Well-Being-Short Form (Ryff, 1989a) was included but those data will not be reported here. It is important to note that there did not appear to be any significant changes in the Ryff measure.

Satisfaction with life scale (SWLS; Diener, Emmons, Larsen, \& Griffin, 1985). The Satisfaction with Life Scale is a five-item measure primarily composed of questions related to satisfaction with one's life. Each of the five questions are answered on a 7-point Likert scale ( 1 = strongly disagree, 7 = strongly agree). Total scores for the SWLS can range from 5 (low satisfaction) to 35 (high satisfaction). Gable, Reis, Impett, and Asher (2004) report the internal consistently coefficient for this scale as .93.

Positive and negative affect schedule (PANAS; Watson, Clark, \& Tellegen, 1988). The PANAS is a 20-item self-report measure used to assess positive affect and negative affect. The measure includes 10 positive affect adjectives and 10 negative affect adjectives. Watson et al. (1988) define positive affect as "the extent to which a person feels enthusiastic, active, and alert" and negative affect as "a general dimension of subjective distress and unpleasurable engagement that subsumes a variety of aversive mood states” (p. 1063). For each adjective, participants are asked to "indicate to what extent you have felt this way during the past week?" by answering on a five-point Likert scale ( 1 = never, 5 = frequently). Possible scores range from 10 to 50 on both the positive and negative subscales. The reliabilities of the PANAS scales is acceptably high with Cronbach's $\alpha$ of .89 for positive affect and .85 for negative affect. The correlation between the positive and negative scales is low at 15 .

Rosenberg self-esteem scale (Rosenberg, 1979). This Rosenberg Self-Esteem Scale aims to measure global self-esteem. The scale consists of 10 items, and asks participants to rate their level of self-respect and degree of satisfaction with themselves in general on a 4-point Likert-type scale. Previous studies have reported alpha reliabilities as ranging from .72 to .88 (Gray-Little, Williams, \& Hancock, 1997) and .88 to .99 (Robins, Hendin, \& Trzesniewski, 2001).

Oxford happiness questionnaire (OHQ; Hills \& Argyle, 2002). The OHQ is an abbreviated measure derived from the OHI (Oxford Happiness Inventory; Argyle, Martin, \& Crossland, 1989). The OHQ was created as a broad measure of happiness and consists of 29 multiple-choice items. Hills and Argyle (2002) adapted the OHI to develop the OHQ by creating 29 single items that are answered on a six point Likert scale $(1=$ strongly disagree, 6 = strongly agree). Hills and Argyle (2002) reported high scale reliabilities with alpha values of .92 for the OHI and .91 for the OHQ.

Also included in the battery were two measures administered in the form of a structured interview.

The well-being interview (WBI; Asselin, 2012). This instrument is a clinician administered, structured clinical interview designed to assess well-being in others. The WBI aims to assess the well-being of individual's across several areas of functioning. The specific subscales assessed are: Overall Well-Being, Satisfaction, Engagement, Purpose, Medical Health, Fitness Habits, Emotion, Relationships, Coping, Identity, Stressors, Affordances and Trajectory. Based on the conceptualizations of subjective well-being and psychological well-being along with contributions from the subfield, positive psychology, the WBI is a measure that is fundamentally rooted in theory. For example, the domain of Satisfaction draws upon Diener's concept of satisfaction with life (Diener, 1984; Diener et al., 1985), Csikszentmihalyi's (1991) theory of Flow, Ryff's (1989b) domain of purpose in life, Watson, Clark, and Tellegen's (1988) research on positive and negative affect, and Seligman's (2002) concept 
of happiness.

In terms of scoring, each domain is comprised of three styles of questions that are read aloud to the participant (e.g., narrative responses, forced-choice responses and Likert-type responses) and then each domain ends with a Likert-type clinician rating based on the participant's responses. Finally, included in the WBI is a brief assessment of mental status so as to assess the participant's presentation and motivation. Responses are then scored based on a scoring rubric and can be used as an intrapersonal assessment of well-being that compliments traditional self-report measures.

For a complete review of the WBI including development, scoring and validation, readers are referred to Asselin (2012).

Supplemental coping questions. The clinician-administered interview also included a supplemental question as an informal measure of the participants' method of coping. Following the administration of the WBI, participants were administered a supplemental measure, which prompted:

You just rated your overall well-being as [insert number from WBI]. Imagine that you just experienced a big stressor or stressors and about a week later your level of overall well-being drops. What are some things you could do over the course of the following week to make yourself feel better? What strategies could you employ?

Based on this prompt the participants then provided the examiner a list of possible actions they would employ (i.e., go for a walk, talk to a friend). The participants were then asked two follow up questions. First, they were asked to rank each provided solution in the order in which they would utilize it (i.e., first, second, third, etc.). Second, participants were asked how likely they would be to utilize each of the provided responses on a scale from 0 (it is highly unlikely that I would do this) to 4 (it is highly likely I would do this).

Open-ended responses to the supplemental coping questions were coded based on category and whether it was adaptive or maladaptive. All responses were double-coded and coded blind of condition. After coding, all responses were analyzed and a total number of unique and adaptive strategies were added for each participant. For example, say a participant listed four coping strategies: "go to the gym”, "work out”, "drink alcohol” and "call a friend". "Go to the gym” and "work out” would each be coded under the category of "exercise” and "drink alcohol" would be considered maladaptive. Therefore, when counting the total number of unique and adaptive coping strategies this participant would have two (exercise and seek social support).

\section{Results}

Due to the convenience sampling and potential for a self-selection bias, comparisons were made between the control and experimental groups prior to exposure to the intervention. Table 2 presents a summary of the demographic backgrounds of the sample and suggests that the groups were largely similar, with the exception of year of college $\mathrm{X}^{2}(3)=25.88, p<.001$, where the control group had higher percentages of juniors and seniors. We also compared the groups on the means of the primary research variables and, as seen in Table 3 , found there were no statistically significant $(p>.05)$ differences between them. These data suggest that the two groups were comparable at baseline.

To determine if there was a time (one and two) by condition (experimental and control) interaction, two-way repeated-measures ANOVAs were conducted for each scale. Means and standard deviations at both collection points are presented in Table 4 and the results of the analyses are presented in Table 5. As depicted in Table 5, the WBI overall score, and the WBI Emotions score had significant interaction effects in the predicted direction, with the intervention group demonstrating more change in the positive direction on these measures than the control group.

A less stringent but also valid comparison was to examine and compare in parallel the respective changes in the two groups on the pre- and post-measures. To achieve this, paired-samples $t$-tests were conducted. Comparisons of T1 and T2 for the experimental group and control group are shown side by side in Table 6. The experimental group demonstrated significant differences between T1 and T2 on the PANAS negative emotions scale, the rosenberg self-esteem scale, and the oxford happiness questionnaire. On the clinician administered WBI, the experimental group demonstrated significant differences on the overall scale, the satisfaction scale, the purpose scale, the emotion scale and the coping scale. Significant differences on the supplemental coping questionnaire suggested that the experimental group identified significantly more unique and adaptive coping strategies following the intervention. 
Table 2. Demographic variables.

\begin{tabular}{ccc}
\hline & Control $(n=32)$ & Intervention $(n=25)$ \\
\hline Age (years) & 20.63 & 20.32 \\
$M$ & 1.48 & 4.55 \\
Gender & $\%$ & $\%$ \\
Male & 18.8 & 24 \\
Female & 81.2 & 76 \\
Race/ethnicity & $\%$ & $\%$ \\
African-American & 6.2 & 0 \\
Asian & 6.2 & 4 \\
Caucasian & 87.5 & 92 \\
Hispanic & 0 & 0 \\
Other & 0 & 4 \\
Year of school & $\%$ & $\%$ \\
Sophomore & 6.2 & 64 \\
Junior & 53.1 & 36 \\
Senior & 37.5 & 0 \\
Other & 3.1 & 0
\end{tabular}

Table 3. Independent samples t-test values on measures of well-being.

\begin{tabular}{|c|c|c|c|c|c|c|c|}
\hline & \multicolumn{2}{|c|}{ Intervention $(\mathrm{n}=25)$} & \multicolumn{2}{|c|}{ Control $(\mathrm{n}=32)$} & \multirow[b]{2}{*}{$t$} & \multirow[b]{2}{*}{$d f$} & \multirow[b]{2}{*}{$p$} \\
\hline Variable & $M$ & $S D$ & $M$ & $S D$ & & & \\
\hline Satisfaction with life scale & 42.2 & 5.4 & 41.6 & 4.1 & -.483 & 55 & .631 \\
\hline Oxford happiness quest & 141.96 & 17.9 & 134.6 & 14.6 & -1.689 & 54 & .064 \\
\hline PANAS: positive emotions & 39.4 & 5.7 & 40.1 & 4.7 & .497 & 54 & .621 \\
\hline PANAS: negative emotions & 19.3 & 4.9 & 19.6 & 5.2 & .269 & 54 & .789 \\
\hline Rosenberg self est. scale & 34.2 & 4.0 & 33.4 & 3.8 & -.778 & 54 & .440 \\
\hline WBI: overall & 98.9 & 7.8 & 101.4 & 7.1 & 1.217 & 54 & .229 \\
\hline WBI: satisfaction & 8.3 & 1.1 & 8.6 & .8 & 1.065 & 54 & .292 \\
\hline WBI: engagement & 8.5 & 1.0 & 8.6 & 1.0 & .647 & 54 & .520 \\
\hline WBI: purpose & 8.7 & 1.1 & 8.7 & 1.0 & -.053 & 54 & .958 \\
\hline WBI: medical health & 8.5 & 1.4 & 9.1 & 1.2 & 1.816 & 54 & .075 \\
\hline WBI: fitness habits & 8.0 & 1.2 & 8.6 & 1.2 & 1.687 & 54 & .097 \\
\hline WBI: emotion & 7.9 & 1.1 & 7.9 & 1.0 & .218 & 54 & .828 \\
\hline WBI: relationships & 8.3 & 1.0 & 8.4 & .82 & .7 & 54 & .487 \\
\hline WBI: coping & 7.8 & .88 & 7.8 & 1.2 & .105 & 54 & .916 \\
\hline WBI: identity & 8.3 & .89 & 8.5 & .94 & 1.1 & 54 & .276 \\
\hline WBI: stressors & 6.9 & 1.1 & 6.8 & 1.2 & -.365 & 54 & .716 \\
\hline WBI: affordances & 8.8 & .85 & 9.0 & .88 & .647 & 54 & .521 \\
\hline WBI: trajectory & 9.1 & .73 & 9.3 & .86 & 1.078 & 54 & .286 \\
\hline Supplemental coping & 3.0 & .93 & 2.8 & 1.2 & .531 & 53 & .598 \\
\hline
\end{tabular}


Table 4. Mean (SD) values for the experimental and control group at pre, post and follow-up.

\begin{tabular}{|c|c|c|c|c|c|c|c|c|c|c|c|c|}
\hline \multirow{3}{*}{ Variable } & \multicolumn{6}{|c|}{ Experimental } & \multicolumn{6}{|c|}{ Control $(n=26)$} \\
\hline & \multicolumn{2}{|c|}{ Time 1} & \multicolumn{2}{|c|}{ Time 2} & \multicolumn{2}{|c|}{ Time 3} & \multicolumn{2}{|c|}{ Time 1} & \multicolumn{2}{|c|}{ Time 2} & \multicolumn{2}{|c|}{ Time 3} \\
\hline & $M$ & $(S D)$ & $M$ & $(S D)$ & $M$ & $(S D)$ & $M$ & $(S D)$ & $M$ & $(S D)$ & $M$ & $(S D)$ \\
\hline Satisfaction with life scale & 42.2 & 5.4 & 42.9 & 4.8 & - & - & 41.4 & 4.2 & 42.7 & 4.5 & - & - \\
\hline Oxford happiness questionnaire & 142 & 17.9 & 146.6 & 15.9 & 143.1 & 14.9 & 134.9 & 14.9 & 140.1 & 15.7 & 140.3 & 12.1 \\
\hline PANAS: positive emotions & 39.4 & 5.7 & 39.1 & 6.5 & 40.8 & 5.5 & 40.2 & 4.4 & 38.9 & 4.5 & 40.6 & 5.0 \\
\hline PANAS: negative emotions & 19.3 & 4.9 & 16.1 & 4.7 & 16.6 & 3.8 & 20.2 & 5.4 & 19.9 & 7.1 & 18.9 & 5.0 \\
\hline Rosenberg self esteem scale & 34.2 & 4.0 & 35.8 & 3.8 & 36.5 & 3.7 & 33.6 & 3.8 & 34.0 & 4.4 & 34.9 & 4.1 \\
\hline WBI: overall & 99.1 & 7.9 & 101.4 & 6.5 & - & - & 101.0 & 6.4 & 101.0 & 6.4 & - & - \\
\hline WBI: satisfaction & 8.3 & 1.1 & 8.8 & .89 & - & - & 8.6 & .74 & 8.6 & .81 & - & - \\
\hline WBI: engagement & 8.5 & .9 & 8.7 & .77 & - & - & 8.8 & .87 & 8.7 & 1.1 & - & - \\
\hline WBI: purpose & 8.7 & 1.1 & 9.0 & .9 & - & - & 8.8 & .79 & 9.2 & .7 & - & - \\
\hline WBI: medical health & 8.5 & 1.5 & 8.4 & 1.5 & - & - & 9.3 & .7 & 9.1 & .78 & - & - \\
\hline WBI: fitness habits & 8.0 & 1.2 & 7.9 & 1.1 & - & - & 8.4 & 1.3 & 8.4 & 1.1 & - & - \\
\hline WBI: emotion & 7.9 & 1.1 & 8.7 & .94 & - & - & 8.0 & 1.0 & 8.1 & 1.1 & - & - \\
\hline WBI: relationships & 8.3 & 1.0 & 8.4 & 1.0 & - & - & 8.4 & .88 & 8.3 & .85 & - & - \\
\hline WBI: coping & 7.9 & .83 & 8.3 & .59 & - & - & 7.8 & 1.1 & 7.7 & 1.1 & - & - \\
\hline WBI: identity & 8.3 & .87 & 8.8 & .71 & - & - & 8.6 & .94 & 8.7 & .87 & - & - \\
\hline WBI: stressors & 6.9 & 1.1 & 6.4 & 1.0 & - & - & 6.8 & 1.2 & 6.2 & 1.1 & - & - \\
\hline WBI: affordances & 8.8 & .87 & 8.9 & .9 & - & - & 8.8 & .93 & 8.8 & .75 & - & - \\
\hline WBI: trajectory & 9.1 & .74 & 9.2 & .68 & - & - & 8.2 & .88 & 9.2 & .72 & - & - \\
\hline Supplemental coping & 3.0 & .93 & 3.5 & .97 & - & - & 2.8 & 1.1 & 3.0 & .94 & - & - \\
\hline
\end{tabular}

Note: Experimental time 1 and time $2 n=25$; experimental time $3 n=17$; control time 1 and time $2 n=32$; control time $3 n=14$.

Table 5. One-way repeated-measures ANOVA values on measures of well-being (time $\times$ group).

\begin{tabular}{|c|c|c|c|}
\hline & $\eta^{2}$ & $F^{a}$ & $p$ \\
\hline Satisfaction with life scale & .005 & .233 & .631 \\
\hline Oxford happiness questionnaire & .000 & .020 & .887 \\
\hline PANAS: positive emotions & .007 & .350 & .557 \\
\hline PANAS: negative emotions & .076 & 4.01 & .051 \\
\hline Rosenberg self esteem scale & .03 & 1.53 & .221 \\
\hline WBI: overall & .099 & 5.25 & $.026^{*}$ \\
\hline WBI: satisfaction & .078 & 4.035 & .050 \\
\hline WBI: engagement & .057 & 2.9 & .095 \\
\hline WBI: purpose & .00 & .021 & .885 \\
\hline WBI: medical health & .00 & .022 & .884 \\
\hline WBI: fitness habits & .006 & .281 & .598 \\
\hline WBI: emotion & .155 & 8.78 & $.005^{*}$ \\
\hline WBI: relationships & .004 & .185 & .669 \\
\hline WBI: coping & .075 & 3.9 & .054 \\
\hline WBI: identity & .063 & 3.21 & .079 \\
\hline WBI: stressors & .002 & .099 & .754 \\
\hline WBI: affordances & .608 & .405 & .527 \\
\hline WBI: trajectory & .026 & 1.284 & .263 \\
\hline Supplemental coping & .5 & 2.79 & .101 \\
\hline
\end{tabular}

Note: ${ }^{\mathrm{a}} d f=(1,49) .{ }^{*} p<.05$. 
Table 6. Repeated measures t-test values on measures of well-being.

\begin{tabular}{|c|c|c|c|c|}
\hline & \multicolumn{2}{|c|}{ Experimental $(n=25)$} & \multicolumn{2}{|c|}{ Control $(n=26)$} \\
\hline & $t(24)$ & $p$ & $t(25)$ & $p$ \\
\hline Satisfaction with life scale & -1.013 & .321 & -1.337 & .193 \\
\hline Oxford happiness questionnaire & -2.074 & $.049^{*}$ & -1.497 & .147 \\
\hline PANAS: positive emotions & .281 & .781 & 1.253 & .222 \\
\hline PANAS: negative emotions & 3.266 & $.003^{*}$ & .291 & .773 \\
\hline Rosenberg self esteem scale & -2.679 & $.013^{*}$ & -.428 & .673 \\
\hline WBI: overall & -2.262 & $.033^{*}$ & .810 & .425 \\
\hline WBI: satisfaction & -4.025 & $.001^{*}$ & -4.35 & .667 \\
\hline WBI: engagement & -1.381 & .181 & .989 & .332 \\
\hline WBI: purpose & --2.115 & $.045^{*}$ & -2.354 & $.027^{*}$ \\
\hline WBI: medical health & .452 & .655 & .723 & .476 \\
\hline WBI: fitness habits & 1.038 & .310 & .399 & .694 \\
\hline WBI: emotion & -4.919 & $.000^{*}$ & -.372 & .713 \\
\hline WBI: relationships & -.427 & .674 & .235 & .816 \\
\hline WBI: coping & -2.136 & $.044^{*}$ & .670 & .509 \\
\hline WBI: identity & -2.55 & $.018^{*}$ & -.731 & .471 \\
\hline WBI: stressors & 1.951 & .063 & 1.862 & .074 \\
\hline WBI: affordances & -.788 & .439 & .160 & .874 \\
\hline WBI: trajectory & -1.056 & .302 & .708 & .486 \\
\hline Supplemental coping & -2.20 & $.038^{*}$ & -.778 & .444 \\
\hline
\end{tabular}

Note: ${ }^{*} p<.05$.

In contrast the to the large number of changes seen between the pre- and post-measures on self-report, clinician administered and the task-oriented coping questionnaire, the control group demonstrated little pre-post change. In fact, the only significant difference for the control group was on the WBI purpose scale. Thus, given the robustness of these findings, it seems that the experimental group did in fact demonstrate improvements in their well-being as assessed by the battery.

Finally, to determine whether changes from T1 to T2 were maintained at T3, paired-samples t-tests were conducted for each condition at T2 and T3 for four self-report measures. Supporting the maintenance hypothesis, no statistically significant differences were evident for either condition between T2 and T3. Table 5 provides the means and standard deviations across the three times and Table 7 reports the findings from the paired-samples t-tests.

\section{Discussion}

The purpose of this research was to determine the impact of a positive psychology course, developed via the lens of Henriques' (2011) integrative meta-theoretical perspective on the happiness and well-being of a group of undergraduate students (see also Henriques, Kleinman, \& Asselin, 2014). It was hypothesized that the course would have a positive, albeit minimal, impact on the undergraduate students enrolled in the course in contrast to students enrolled in an elective psychology course that served as controls. It was further hypothesized that the gains would be maintained at follow-up. It was hypothesized that the impact would be minimal because these students were selected from the general population, and thus were not included because of any a priori difficulties. As such, it was debatable as to whether any impact at all would be found, especially in a group of only twenty-five individuals. 
Table 7. Repeated measures t-test values on measures of well-being from pre-test to follow-up.

\begin{tabular}{cccccc}
\hline & \multicolumn{2}{c}{ Experimental } & \multicolumn{2}{c}{ Control } \\
\hline Oxford happiness questionnaire & $t(16)$ & $p$ & $t(13)$ & $p$ \\
\hline PANAS: positive emotions & 1.59 & .131 & 1.98 & .074 \\
PANAS: negative emotions & -1.14 & .269 & -1.35 & .204 \\
Rosenberg self esteem scale & .146 & .886 & .809 & .434 \\
\hline
\end{tabular}

Note: ${ }^{*} p<.05$.

There are additional reasons as to why one might be skeptical in seeing a significant change in well-being in a general sample stemming from one course. Research has found that well-being is considered to be reasonably stable over time (Eid \& Diener, 2004), and it is easy to argue that one undergraduate course will have a relatively limited impact on a general population. Additionally, the concept of the hedonic treadmill (Brickman \& Campbell, 1971) and the revised adaptation theory of well-being (Diener, Lucas, \& Scollon, 2006) raise questions about changes in well-being. Specifically suggesting that individuals have a set point of happiness and that emotional experiencing is similar to the process of sensory adaptation, meaning that people become habituated to their emotions just like people become habituated to a sound or smell. As such, while it is expected that levels of well-being occasionally change, it is also expected that ultimately the level of well-being will return to an individual set-point or baseline.

The data comparing the two groups on the battery of well-being assessments-which included several common self-report measures of well-being and related constructs, a newly developed clinician-administered measure of well-being, and a task oriented coping measure-pointed strongly to the intervention having a positive impact. Indeed, the impact was more notable and reliable than we originally guessed.

Our initial and most stringent analyses involved looking for a time (pre-post) by group (experimental-control) interaction effect on the various measures. Through this data analytic lens, significant interaction effects were found on the overall well-being scale and the emotions subscale of the well-being interview, showing that the experimental group demonstrated significantly greater levels of change in the positive direction than the control group. Furthermore, although not significant at the level of a traditional statistical cutoff, it is worth noting that three scales (the PANAS negative emotions, WBI satisfaction subscale and the WBI coping subscale) approached significance for interaction effects.

The less stringent, but also reasonable group comparison was made by examining the paired sample pre-post differences. We found the experimental group exhibited significant improvements on each of the variables we assessed. That included the three self-report scales [PANAS (negative affect score), the Rosenberg Self-Esteem Scale and the Oxford Happiness Questionnaire], the clinician administered WBI (including the overall scale, the satisfaction subscale, the emotions subscale and the coping subscale), and the task oriented supplemental coping questions. It is worth noting again here that, in contrast to these positive findings, the Ryff scales of psychological well-being were also administered but there were no changes observed in any of the scales or groups.

The follow-up data, collected four months following completion of the course, were also encouraging. The main research question explored here was to see whether compared to posttest data, at completion of the course, if the participant's levels of well-being would remain the same, return to the baseline, or continue to improve. It was hypothesized that follow-up data would remain the same as posttest data. Supporting this hypothesis, results indicated no significant change in well-being from posttest to follow-up.

The present study represented a pilot investigation aimed at testing the effectiveness of a course designed to enhance the well-being of undergraduate students. As such, and due to the exploratory nature of the present study, there are certain limitations that caution against the generalizability of the findings and a direct causal relationship cannot be made. Nonetheless, it is the hope that by recognizing the limitations, future research can more carefully and closely explore the construct, thereby contributing to the already impressive body of research.

An initial limitation relates to the recruitment and enrollment of students in both the control and experimental condition. The convenience sampling approach, in that students self-selected into the courses, limits comparabil- 
ity and may suggest group differences prior to the intervention. This was recognized and managed by comparing demographics and baseline scores on the battery between groups, but nonetheless an improved design would have randomly assigned participants into the conditions. The demand characteristics of the experimental group represent a limitation regarding exact interpretation of the magnitude of impact of the study. Another limitation, which leads to future research, is related to the complexity inherent in an undergraduate course that includes multiple components (i.e., lectures, homework, small-group, etc.). Therefore, by parsing apart the different components, a more clear understanding of the mechanisms behind the observed change would be understood.

After more carefully understanding the effective component or combination of components, future studies might expand these findings by adapting the intervention to different populations. Of primary interest to this researcher is in creating a downward expansion of the research so that it can be applied to children and adolescents. Ideally, it could function as a preventative measure aimed at teaching the components of a healthy lifestyle and adaptive coping strategies prior to the emergence of psychopathology that may become incorporated into the school curriculum.

In terms of college samples, Arkoff et al. (2006) point out that a particularly difficult time for students occurs near their entrance to college, as such, it is wondered whether a course of this nature would also be suitable for a freshman seminar or orientation experience. Similar to other orientation or freshman seminar courses, this course combines both academic lessons with more personalized life and developmental lessons. Therefore making this course ideally suited for students during a transitional phase.

If not serving as a preventative measure, future explorations may also look at an adapted version of the intervention and develop it into a 10-week psychoeducational group aimed at improving the well-being of members. Specifically, it may be effective for patients diagnosed with affective disorders, adjustment disorders or possibly more pervasive personality or relational disorders.

\section{Conclusion}

Overall, as highlighted in the introduction, college is a time where stress accumulates and more recently where the emergence of psychopathology has reached unprecedented levels. In a survey of the directors of college counseling centers, $70 \%$ reported believing there to be an increase in students with severe psychological problems on their campuses and 95\% reported that the number of students with significant psychological problems to be a growing concern (AUCCCD, 2012). As such, educators and researchers have suggested altering the culture and/or curriculum on campuses so as to purposefully foster well-being. At the same time, the flourishing of positive psychology within the larger field of psychology, has led many institutions to include positive psychology courses within the curriculum. With this in mind, the findings of the current study suggest that the well-being of students can be improved in the context of an undergraduate course. And from a more applied perspective, the study offers exciting possibilities for the future of prevention and intervention.

\section{References}

American College Health Association. American College Health Association National College Health\Assessment (ACHANCHA) (2013). Spring 2013 Reference Group Executive Summary: The American College Health Association. http://www.acha-ncha.org/docs/ACHA-NCHA-II_UNDERGRAD_ReferenceGroup_ExecutiveSummary_Spring2013.pdf

Argyle, M., Martin, M., \& Crossland, J. (1989). Happiness as a Function of Personality and Social Encounters. In J. P. Forgas, \& J. M. Innes (Eds.), Recent Advances in Social Psychology: An International Perspective (pp. 189-247). NorthHolland: Elsevier Science Publishers B.V.

Arkoff, A., Meredith, G. M., Bailey, E., Cheang, M., Dubanoski, R. A., Griffin, P. B., \& Niyekawa, A. M. (2006). Life Review during the College Freshman Year. College Student Journal, 40, 263-269.

Arkoff, A. (1999). The Illuminated Life: Your Lifebook. Self-Published.

Asselin, C. A. (2012). The Development of the Well-Being Interview. Unpublished Doctoral Dissertation, Harrisonburg, VA: James Madison University.

Association for University and College Counseling Center Directors (AUCCCD) (2012). AUCCCD 2012 Survey. http://files.cmcglobal.com/Monograph_2012_AUCCCD_Public.pdf

Brickman, P., \& Campbell, D. T. (1971). Hedonic Relativism and Planning the Good Science. In M. H. Appley (Ed.), Adaptation Level Theory: A Symposium (pp. 287-302). New York: Academic Press.

Csikszentmihalyi, M. (1991). Flow: The Psychology of Optimal Experience: Steps toward Enhancing the Quality of Life. New York: Harper Collins Publishers. 
Diener, E. (1984). Subjective Well-Being. Psychological Bulletin, 95, 542-575. http://dx.doi.org/10.1037/0033-2909.95.3.542

Diener, E., Emmons, R. A., Larsen, R. J., \& Griffin, S. (1985). The Satisfaction with Life Scale. Journal of Personality Assessment, 49, 71-75. http://dx.doi.org/10.1207/s15327752jpa4901 13

Diener, E., Lucas, R. E., \& Scollon, C. N. (2006). Beyond the Hedonic Treadmill: Revising the Adaptation Theory of Well-Being. American Psychologist, 61, 305-314. http://dx.doi.org/10.1037/0003-066X.61.4.305

Eid, M., \& Diener, E. (2004). Global Judgments of Subjective Well-Being: Situational Variability and Long-Term Stability. Social Indicators Research, 65, 245-277. http://dx.doi.org/10.1023/B:SOCI.0000003801.89195.bc

Fredrickson, B. L. (2004). The Broaden-and-Build Theory of Positive Emotions. Philosophical Transactions of the Royal Society B: Biological Sciences, 359, 1367-1377. http://dx.doi.org/10.1098/rstb.2004.1512

Fredrickson, B. L., \& Branigan, C. (2005). Positive Emotions Broaden the Scope of Attention and Thought-Action Repertoires. Cognition and Emotion, 19, 313-332. http://dx.doi.org/10.1080/02699930441000238

Gable, S. L., Reis, H. T., Impett, E. A., \& Asher, E. R. (2004). What Do You Do When Things Go Right? The Intrapersonal and Interpersonal Benefits of Sharing Positive Events. Journal of Personality and Social Psychology, 87, 228-245. http://dx.doi.org/10.1037/0022-3514.87.2.228

Gallagher, R. P. (2003). National Survey of Counseling Center Directors 2003. Alexandria, VA: International Association of Counseling Services.

Gray-Little, B., Williams, V. S. L., \& Hancock, T. D. (1997). An Item Response Theory Analysis of the Rosenberg SelfEsteem Scale. Personality and Social Psychology Bulletin, 23, 443-451. http://dx.doi.org/10.1177/0146167297235001

Henriques, G. (2011). A New Unified Theory of Psychology. New York: Springer Science + Business Media. http://dx.doi.org/10.1007/978-1-4614-0058-5

Henriques, G. R., Kleinman, K., \& Asselin, C. (2014). The Nested Model of Well-Being: A Unified Approach. Review of General Psychology, 18, 7-18. http://dx.doi.org/10.1037/a0036288

Hills, P., \& Argyle, M. (2002). The Oxford Happiness Questionnaire: A Compact Scale for the Measurement of Psychological Well-Being. Personality and Individual Differences, 33, 1073-1082. http://dx.doi.org/10.1016/S0191-8869(01)00213-6

Lyubomirsky, S., King, L., \& Diener, E. (2005). The Benefits of Frequent Positive Affect: Does Happiness Lead to Success? Psychological Bulletin, 131, 803-855. http://dx.doi.org/10.1037/0033-2909.131.6.803

Lyubomirsky, S. (2007). The How of Happiness: A Scientific Approach to Getting the Life You Want. New York: Penguin Press.

Oades, L. G., Robinson, P., Green, S., \& Spence, G. B. (2011). Towards a Positive University. The Journal of Positive Psychology, 6, 432-439. http://dx.doi.org/10.1080/17439760.2011.634828

Pawelski, J. O. (2003). Character as Ethical Democracy: Definitions and Measures. Journal of College and Character, 5. http://dx.doi.org/10.2202/1940-1639.1398

Quinn, P. D., \& Duckworth, A. L. (2007). Happiness and Academic Achievement: Evidence for Reciprocal Causality. The Annual Meeting of the American Psychological Society, 24-27 May 2007.

Robins, R. W., Hendin, H. M., \& Trzensniewski, K. H. (2001). Measuring Global Self-Esteem: Construct Validation of a Single-Item Measure and the Rosenberg Self Esteem Scale. Personality and Social Psychology Bulletin, 27, 151-161. http://dx.doi.org/10.1177/0146167201272002

Rosenberg, M. (1979). Conceiving the Self. New York: Basic Books.

Ryan, R., \& Deci, E. (2001). On Happiness and Human Potentials: A Review of Research on Hedonic and Eudaimonic WellBeing. Annual Review of Psychology, 52, 141-166. http://dx.doi.org/10.1146/annurev.psych.52.1.141

Ryff, C. D. (1989a). Happiness Is Everything, or Is It? Explorations on the Meaning of Psychological Well-Being. Journal of Personality and Social Psychology, 57, 1069-1081. http://dx.doi.org/10.1037/0022-3514.57.6.1069

Ryff, C. D. (1989b). Beyond Ponce de Leon and Life Satisfaction: New Directions in Quest of Successful Ageing. International Journal of Behavioral Development, 12, 35-55. http://dx.doi.org/10.1177/016502548901200102

Seligman, M. E. P. (2002). Authentic Happiness: Using the New Positive Psychology to Realize Your Potential for Lasting Fulfillment. New York: Free Press.

Seligman, M. E. P., Ernst, R. M., Gillham, J., Reivich, K., \& Linkins, M. (2009). Positive Education: Positive Psychology and Classroom Interventions. Oxford Review of Education, 35, 293-311. http://dx.doi.org/10.1080/03054980902934563

Shapiro, S. L., Schwartz, G. E. R., \& Santerre, C. (2005). Meditation and Positive Psychology. In C. R. Snyder, \& S. J. Lopez (Eds.), Handbook of Positive Psychology. Cary, NC: Oxford University Press.

Sin, N. L., \& Lyubomirsky, S. (2009). Enhancing Well-Being and Alleviating Depressive Symptoms with Positive Psychology Interventions: A Practice-Friendly Meta-Analysis. Journal of Clinical Psychology, 65, 467-487.

http://dx.doi.org/10.1002/jclp.20593 
Van Boven, L., \& Ashworth, L. (2007). Looking forward, Looking back: Anticipation Is More Evocative than Retrospection. Journal of Experimental Psychology: General, 136, 289-300. http://dx.doi.org/10.1037/0096-3445.136.2.289

Watson, D., Clark, L., \& Tellegen, A. (1988). Development and Validation of Brief Measures of Positive and Negative Affect: The PANAS Scales. Journal of Personality and Social Psychology, 54, 1063-1070.

http://dx.doi.org/10.1037/0022-3514.54.6.1063

\section{Appendix}

Table A1. Sample depiction of weekly course content and structure.

\begin{tabular}{|c|c|}
\hline Component & Description \\
\hline Topic: & Emotions and emotion regulation \\
\hline Lecture: & $\begin{array}{l}\text { Original PowerPoint to lead class in discussion-based lecture. } \\
\text { Students were expected to complete reading prior to class in order to inform educated discussion. }\end{array}$ \\
\hline $\begin{array}{l}\text { Assigned } \\
\text { reading: }\end{array}$ & $\begin{array}{l}\text { 1) The broaden-and-build theory of positive emotions }{ }^{1} \text {. } \\
\text { 2) Meditation and positive psychology }{ }^{2} \text {. } \\
\text { 3) Looking forward, looking back: anticipation is more evocative than retrospection }{ }^{3} \text {. }\end{array}$ \\
\hline $\begin{array}{l}\text { Homework } \\
\text { assignment: }\end{array}$ & $\begin{array}{l}\text { Practice mindfulness meditation each day for } 15 \text { - } 20 \text { minutes. You can begin with } 10 \text { minutes and work your way } \\
\text { to } 20 \text { if you like. The point of this exercise is to simply observe your thoughts and feelings with an open and } \\
\text { non-judgmental attitude, not to achieve some specific result. Carefully read the handout for specific instructions }{ }^{4} \text {. }\end{array}$ \\
\hline $\begin{array}{l}\text { Journal } \\
\text { prompt: }\end{array}$ & $\begin{array}{l}\text { Before and after each day's meditation write a few notes about the thoughts, feelings, difficulties, or questions } \\
\text { that came to mind before, during and after sitting. At the end of the week review your notes and write a brief } \\
\text { description of your mindful practice experience. Does it make sense that the cultivation of mindfulness through } \\
\text { mindfulness meditation can lead to enhanced well-being? Discuss and explain your opinion. }\end{array}$ \\
\hline $\begin{array}{l}\text { Suggested } \\
\text { discussion } \\
\text { points for } \\
\text { small group: }\end{array}$ & $\begin{array}{l}\text { General questions } \\
\text { - What emotions are you most comfortable feeling? What emotions do you prefer not to feel? } \\
\text { - Would you say most people are aware of their feelings? Were you aware of them before talking about them today? } \\
\text { - Why is emotional intelligence important? } \\
\text { - Is it hard to regulate your emotions? What makes it easier? Harder? } \\
\text { - } \text { friends with them? } \\
\text { - If you could only feel one emotion what would it be? Why? } \\
\text { - How do positive emotions build personal resources? Example? } \\
\text { - How you think of a counter-example to this theory? That is, a negative effect of a positive emotion? }\end{array}$ \\
\hline
\end{tabular}

Note: ${ }^{1}$ Fredrickson, 2004; ${ }^{2}$ Shapiro, Schwartz \& Santerre, 2005; ${ }^{3}$ Van Boven \& Ashworth, 2007; ${ }^{4}$ Lyubomirsky, 2007. 
Scientific Research Publishing (SCIRP) is one of the largest Open Access journal publishers. It is currently publishing more than 200 open access, online, peer-reviewed journals covering a wide range of academic disciplines. SCIRP serves the worldwide academic communities and contributes to the progress and application of science with its publication.

Other selected journals from SCIRP are listed as below. Submit your manuscript to us via either submit@scirp.org or Online Submission Portal.
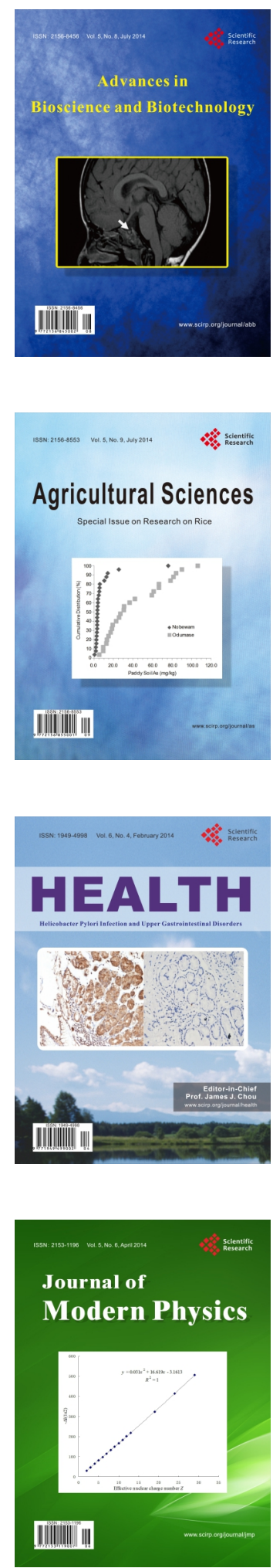
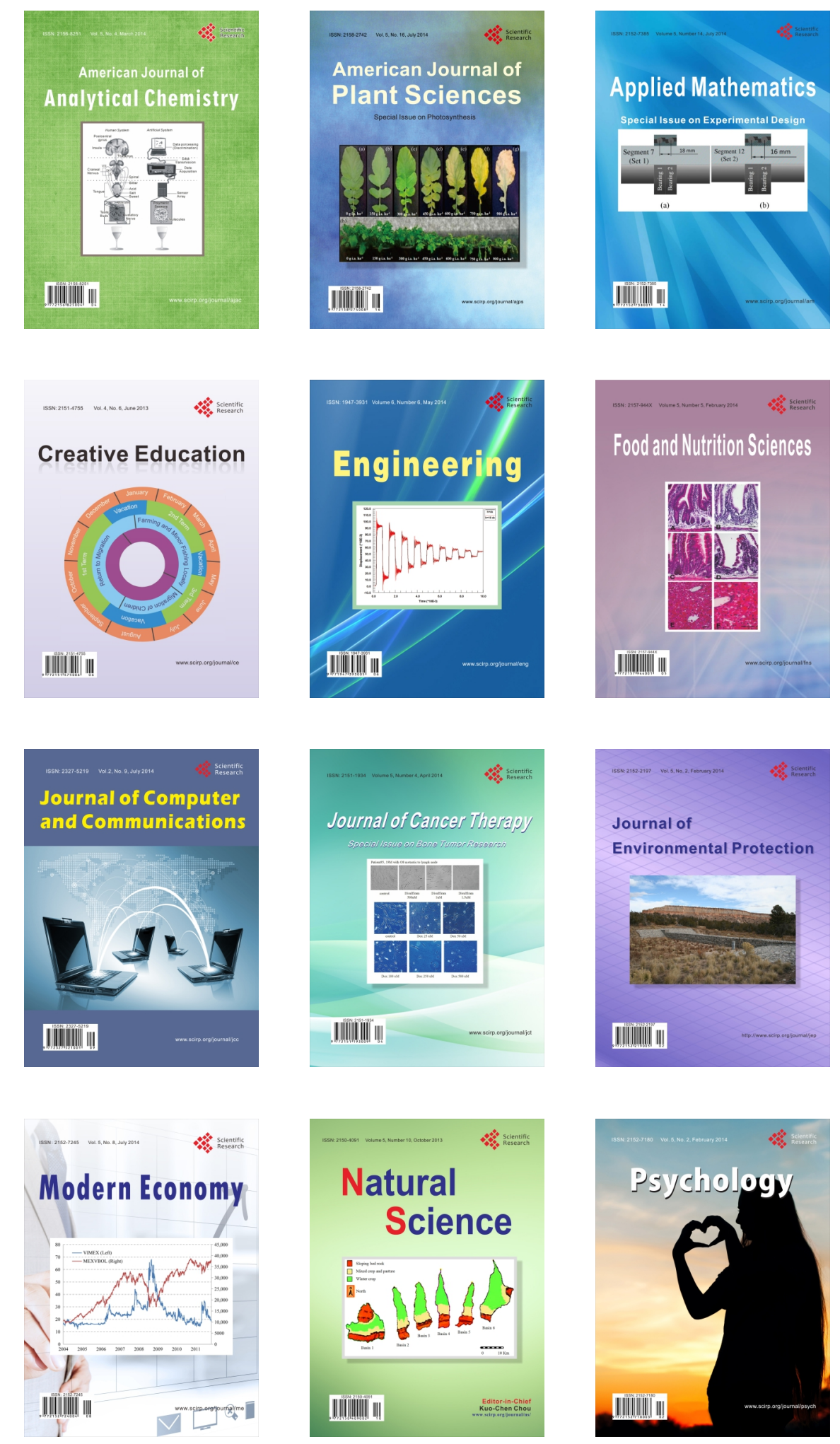